\title{
Experimental Study on Unconfined Compressive Strength of Basalt Fiber Reinforced Clay Soil
}

\author{
Lei Gao, Guohui Hu, Nan Xu, Junyi Fu, Chao Xiang, and Chen Yang \\ Key Laboratory of Geomechanics and Embankment Engineering, Ministry of Education, Hohai University, Nanjing 210098, China \\ Correspondence should be addressed to Lei Gao; taiyang360@gmail.com
}

Received 29 March 2015; Revised 15 August 2015; Accepted 18 August 2015

Academic Editor: Jainagesh A. Sekhar

Copyright (C) 2015 Lei Gao et al. This is an open access article distributed under the Creative Commons Attribution License, which permits unrestricted use, distribution, and reproduction in any medium, provided the original work is properly cited.

\begin{abstract}
In order to study the mechanism and effect of basalt fiber reinforced clay soil, a series of unconfined compressive strength tests conducted on clay soil reinforced with basalt fiber have been performed under the condition of optimum water content and maximum dry density. Both the content and length of basalt fiber are considered in this paper. When the effect of content is studied, the $12 \mathrm{~mm}$ long fibers are dispersed into clay soil at different contents of $0.05 \%, 0.1 \%, 0.15 \%, 0.20 \%, 0.25 \%, 0.30 \%$, and $0.35 \%$. When the effect of length is researched, different lengths of basalt fibers with $4 \mathrm{~mm}, 8 \mathrm{~mm}, 12 \mathrm{~mm}$, and $15 \mathrm{~mm}$ are put into soil at the same content of $0.05 \%$. Experimental results show that basalt fiber can effectively improve the UCS of clay soil. And the best content and length are $0.25 \%$ and $12 \mathrm{~mm}$, respectively. The results also show that the basalt fiber reinforced clay soil has the "poststrong" characteristic. About the reinforcement mechanism, the fiber and soil column-net model is proposed in this paper. Based on this model and SEM images, the effect of fiber content and length is related to the change of fiber-soil column and formation of effective fiber-soil net.
\end{abstract}

\section{Introduction}

Natural clay soil material has certain deficiency in the strength and stability of foundation. The study and application of introducing new materials to clay soil will improve the strength of clay soil foundation, as well as foundation instability to some extent. At present, the materials used in reinforcing soil are mainly fiber, metal, geosynthetics, georgia, geotextiles, and so on. Among them, the fibrous material has the features of tensile, anticracking, acid, and alkali resistance. In recent years, the research about adding fiber materials to reinforce clay soil has been paid more attention in geotechnical engineering [1-3]. Currently, the fibers used in the soil can be mainly divided into two types: natural fiber and artificial synthetic fiber. In case of acid environment, the natural fiber hydrolyses easily reduce the strength, which affects the reinforcing effect. So it is difficult to be adapted to the complex and diverse environment. Among the artificial synthetic fibers, the polypropylene fiber is the most commonly used fiber in the engineering. However, the mechanical properties of polypropylene fiber such as the tensile strength and elastic modulus are limited and its reinforcing effect is largely limited by the type of soil [4-7].
The basalt fiber is an inorganic fiber which uses natural basalt ore as raw material, and the natural basalt ore is crushed to a certain size, then put into the melting furnace, and drawn at $1450^{\circ} \mathrm{C}-1500^{\circ} \mathrm{C}$. The basalt fiber has natural compatibility, excellent mechanical properties, high temperature, and acid and alkali resistance. It is widely used as the insulation, sound absorption, heat-resistant materials, and reinforced materials in thermosetting resin and concrete [8-13]. Compared with the conventional fibers, the price of basalt fiber is only $1 / 10$ of that of carbon fiber. In addition, the mechanical properties like the tensile strength and elastic modulus of basalt fiber are significantly higher than those of polypropylene fiber. Now, there are many studies of modified concrete, in which the basalt fiber is applied as the admixture, but the outcomes of basalt fiber applied to the clay soil are relatively few. For the mechanism of basalt fiber reinforcement, the influence of content and length on reinforcement effect is not clear, so it is particularly important to study the basalt fiber reinforced clay soil.

In this paper, the basalt fiber is added into clay soil, and the unconfined compressive strength (UCS) test and scanning electron microscope (SEM) test are performed in 
TABle 1: Physical-mechanical behaviors of basalt fiber.

\begin{tabular}{lccccc}
\hline Density $/\left(\mathrm{g} / \mathrm{cm}^{3}\right)$ & Elastic modulus/GPa & Elongation at break/\% & Tensile strength $/ \mathrm{MPa}$ & Length $/ \mathrm{mm}$ & Filament diameter/ $\mu \mathrm{m}$ \\
\hline 2.65 & 85.9 & 3.12 & 2611 & 15 & 17 \\
\hline
\end{tabular}

TABLe 2: Physical behaviors of clay soil.

\begin{tabular}{|c|c|c|c|c|c|c|c|c|c|c|c|}
\hline \multirow[b]{2}{*}{$\begin{array}{l}\text { Liquid limit } \\
W_{L} / \%\end{array}$} & \multirow[b]{2}{*}{$\begin{array}{l}\text { Plasticity } \\
\text { index } I_{p}\end{array}$} & \multirow[b]{2}{*}{$\begin{array}{l}\text { Optimum water } \\
\text { content } w_{\mathrm{op}} / \%\end{array}$} & \multirow[b]{2}{*}{$\begin{array}{c}\text { Maximum dry } \\
\text { density } \rho_{d} /\left(\mathrm{g} \cdot \mathrm{cm}^{-3}\right)\end{array}$} & \multicolumn{3}{|c|}{ Percentage of particles/\% } & \multirow[b]{2}{*}{$D_{60}$} & \multirow[b]{2}{*}{$D_{30}$} & \multirow[b]{2}{*}{$D_{10}$} & \multirow[b]{2}{*}{$C_{u}$} & \multirow[b]{2}{*}{$C_{c}$} \\
\hline & & & & $\begin{array}{c}2 \sim 0.075 \\
\mathrm{~mm}\end{array}$ & $\begin{array}{c}0.075 \sim 0.005 \\
\mathrm{~mm}\end{array}$ & $\begin{array}{c}<0.005 \\
\mathrm{~mm}\end{array}$ & & & & & \\
\hline 27.2 & 10 & 17.0 & 1.72 & 43 & 42 & 15 & 0.081 & 0.028 & 0.004 & 19.8 & 2.4 \\
\hline
\end{tabular}

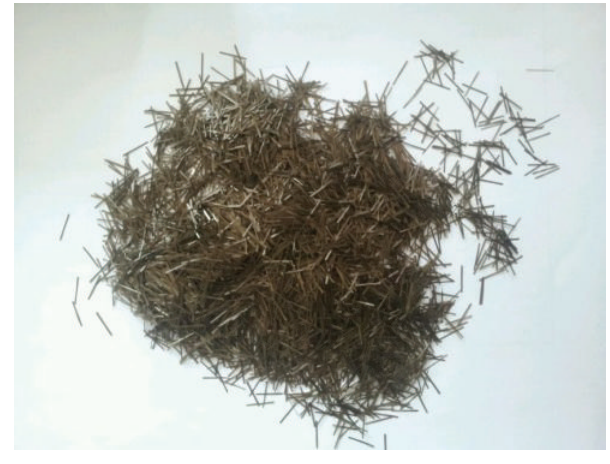

Figure 1: Basalt fiber.

the laboratory to analyze the effects of basalt fiber reinforced clay soil. Then its reinforcement mechanism is discussed with SEM images. Based on the analyses of interaction between the basalt fiber and soil, this paper proposes that the basalt fiber reinforced clay soil has the "poststrong" characteristic and the fiber and soil column-net model is introduced. The results can be applied as the reference for basalt fiber reinforced clay soil engineering.

\section{Materials}

2.1. Basalt Fiber. The basalt fiber used in the test can be seen in Figure 1, and the lengths of basalt fiber are $4 \mathrm{~mm}, 8 \mathrm{~mm}$, $12 \mathrm{~mm}$, and $15 \mathrm{~mm}$. Before being dispersed into soil specimen, the strip basalt fiber is torn and then evenly incorporated into the clay soil. The basalt fiber is filamentous; its basic physical and mechanical parameters are shown in Table 1.

2.2. Physical Properties of Soil. The soil used in the test is taken from a construction site in Nanjing. Before the test, its physical properties are obtained, as shown in Table 2. After analyzing, the soil is a kind of clay soil with low liquid limit.

\section{Testing}

3.1. Test Program. In order to study the effect of fiber content on the UCS of clay soil, the length of basalt fiber is $12 \mathrm{~mm}$ and the mass percentages of dry soil are, respectively, $0 \%, 0.05 \%$, $0.10 \%, 0.15 \%, 0.20 \%, 0.25 \%, 0.30 \%$, and $0.35 \%$. Eight groups of basalt fiber reinforced soil samples are prepared with three
TABle 3: Parameters of soil samples.

\begin{tabular}{lcc}
\hline $\begin{array}{l}\text { Index number of soil } \\
\text { samples }\end{array}$ & $\begin{array}{c}\text { Content of basalt } \\
\text { fiber/\% }\end{array}$ & $\begin{array}{c}\text { Length of basalt } \\
\text { fiber/mm }\end{array}$ \\
\hline S1 & 0.00 & 0 \\
S2 & 0.05 & 12 \\
S3 & 0.10 & 12 \\
S4 & 0.15 & 12 \\
S5 & 0.20 & 12 \\
S6 & 0.25 & 12 \\
S7 & 0.30 & 12 \\
S8 & 0.35 & 12 \\
S9 & 0.05 & 4 \\
S10 & 0.05 & 8 \\
S11 & 0.05 & 15 \\
\hline
\end{tabular}

parallel samples for each one. The effect of fiber length on the UCS of clay soil is studied, and 3 kinds of length are chosen as $4 \mathrm{~mm}, 8 \mathrm{~mm}$, and $15 \mathrm{~mm}$. Compared with the group for the length of fiber with $12 \mathrm{~mm}$, they are dispersed into soil at the same content $0.05 \%$. In total, 11 groups of samples are prepared. The relevant parameters of soil samples are shown in Table 3.

3.2. Samples Preparation. The preparation process of basalt fiber reinforced soil samples for UCS is as follows: firstly, a certain mass of basalt fiber is mixed with air-dried soil evenly; secondly, the quantitative water is stirred together with soil to the preparation of optimum soil water content; thirdly, the samples are put in the humidor for 20 hours. The pressure method is used in the preparation of samples [14], which is divided into 5 layers and compacted. The height of the sample is $80 \mathrm{~mm}$ and diameter is $39.1 \mathrm{~mm}$. After their formation is finished, the method of vacuum saturation is used to make the soil sample saturated, and then the UCS of soil samples is tested. Finally, the representative soil samples are selected from the broken samples of UCS for SEM. The low-temperature baking method is used in the preparation of SEM samples due to the low soil water content and little shrinkage deformation of soil samples.

3.3. Test Instrument. The UCS test instrument used in this paper is YYW-2 unconfined compressive strain control 


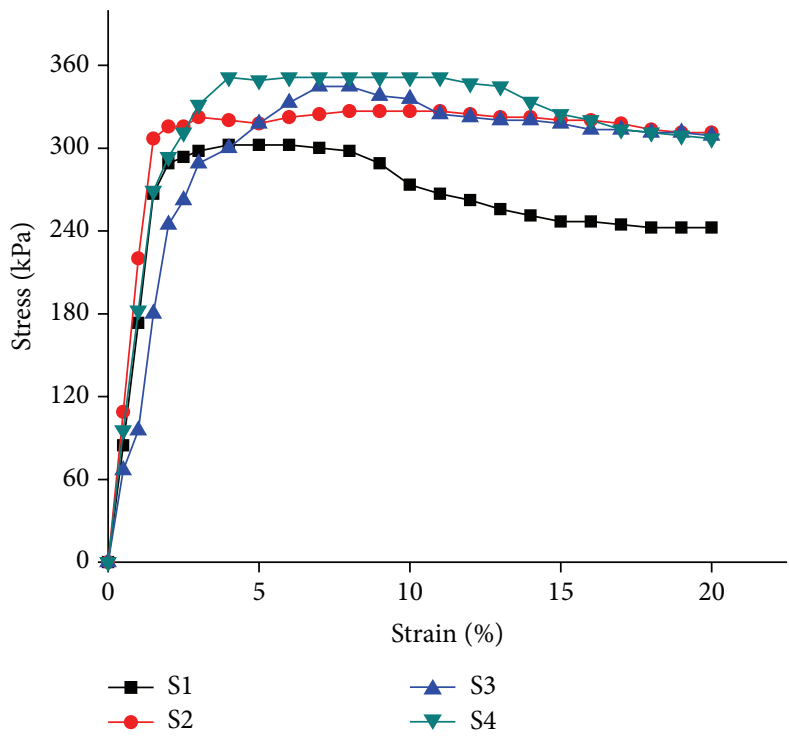

(a) S1 S4

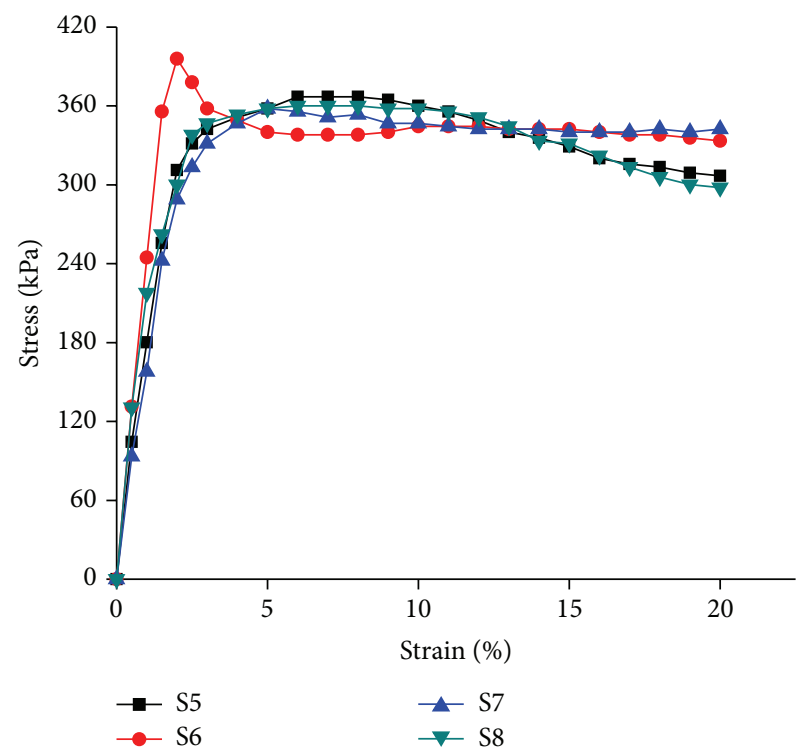

(b) $\mathrm{S} 5 \sim \mathrm{S} 8$

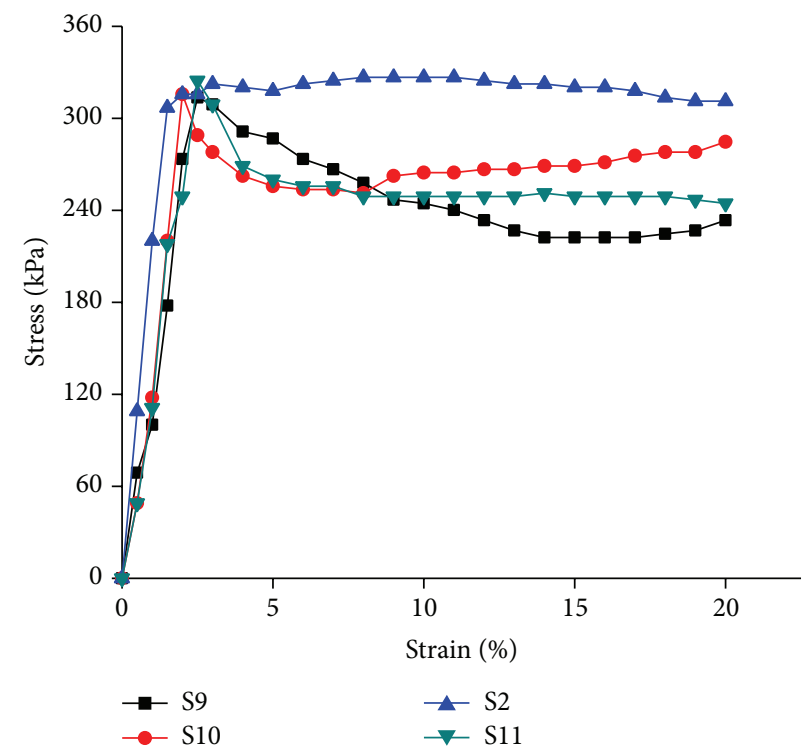

(c) S2, S9 S11

FIGURE 2: Stress-strain curves of unconfined compressive strength for the samples.

device produced by Nanjing Soil Instrument Manufacturer. The controlling strain rate is $2.4 \mathrm{~mm} / \mathrm{min}$ and the test for one sample lasts for about 7 minutes. The SEM analyses were performed on Hitachi S-4800 electronic microscope, with optical system, vacuum system, and imaging system. The resolving power can reach $1 \mathrm{~nm}$.

\section{Results and Analyses}

Figure 2 is the stress-strain curves of the UCS of soil samples, the content of basalt fiber is different, and the length is $12 \mathrm{~mm}$ in Figures 2(a) and 2(b); the length of basalt fiber is different and the content of basalt fiber is $0.05 \%$ in Figure 2(c). What can be seen from the figure is that the stress-strain curves of soil sample without fiber and basalt fiber reinforced soil samples are approximately linear at the initial stage, the axial stress increases with the increase of axial strain, and the rate is a little large. The early compression stiffness is approximately equal. After the sample is broken, the stress-strain curves of the basalt fiber reinforced soil have a downward trend, the decreasing range is not huge, and it decreases more gently than that of soil sample without fiber. Some curves of basalt fiber reinforced soil sample, such as the curve of S10 sample, rise contrarily and late reach the higher compressive strength, and they show a certain destructive toughness. The S7 sample which has the relatively high content of basalt fiber shows the high destructive toughness in the later stage. 
TABLE 4: Unconfined compressive strengths of soil samples.

\begin{tabular}{lcc}
\hline Number & UCS/kPa & $\begin{array}{c}\text { Percentage of strength } \\
\text { improving/\% }\end{array}$ \\
\hline S1 & 302.4 & 0.00 \\
S2 & 326.8 & 8.07 \\
S3 & 344.6 & 13.96 \\
S4 & 351.3 & 16.20 \\
S5 & 366.9 & 21.33 \\
S6 & 395.8 & 30.89 \\
S7 & 358.0 & 18.39 \\
S8 & 360.2 & 19.11 \\
S9 & 313.5 & 3.67 \\
S10 & 315.7 & 4.40 \\
S11 & 324.6 & 7.34 \\
\hline
\end{tabular}

The UCS test results of samples are analyzed; according to the Chinese geotechnical test method standard [14], the peak or stable values of stress-strain curves can be taken as the UCS of samples. About the curves without peak or stable values, the axial stress corresponding to $15 \%$ of the axial strain in stress-strain curves can be taken as the UCS of soil sample, and then Table 4 is obtained. It can be seen from the table that the UCS of soil samples can be improved by using different lengths and contents of basalt fiber, and the highest increasing ratio reaches $30.89 \%$.

Figure 3 shows the effect of basalt fiber content on the UCS of soil samples. It can be known from the figure that when the length of fiber is the same, the UCS variations of fiber reinforced soil samples are similar to the trend of first increasing and then decreasing with the increase of fiber content. When the fiber content increases to $0.25 \%$, the UCS of soil sample reaches the peak at $395.8 \mathrm{kPa}$. Then the UCS of soil is on the decline with the continual increasing of fiber content. It shows that the UCS of basalt fiber reinforced soil samples is associated with the content of fiber. When the fiber content is $0.25 \%$, the UCS of soil reaches the maximum.

Figure 4 shows the effect of basalt fiber length on the UCS of soil samples. It can be seen from the figure that when the fiber content is the same, with the increase of fiber length, the UCS of fiber reinforced soil increases first and then decreases. When the fiber length is $12 \mathrm{~mm}$, the UCS of the soil reaches the peak at $326.8 \mathrm{kPa}$. Then the UCS of the soil drops slightly with the increasing of fiber length. This shows that the UCS of fiber reinforced soil is associated with the length of fiber, and when the fiber length is $12 \mathrm{~mm}$, the UCS of the soil reaches the maximum.

\section{Discussions}

5.1. "Poststrong" Characteristic of Fiber Reinforced Soil. An obvious phenomenon can be found in the stress-strain curves from Figure 2; they are almost strain softening. After the sample reaches comparatively large stress initially, the strength generally begins to decline with increasing of the strain. However, the decline process of fiber reinforced soil is

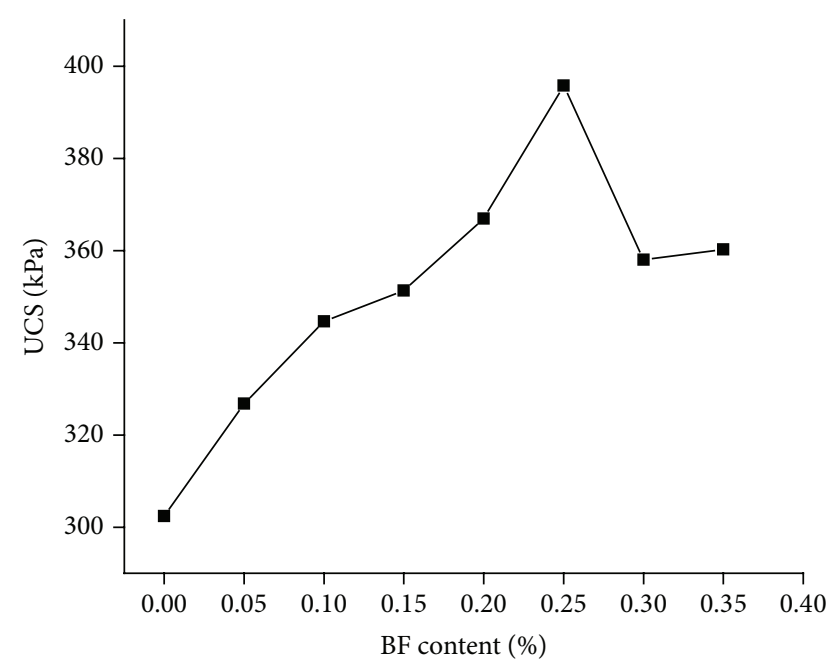

FIGURE 3: Effect of basalt fiber (BF) content on unconfined compressive strength (UCS) of soil samples.

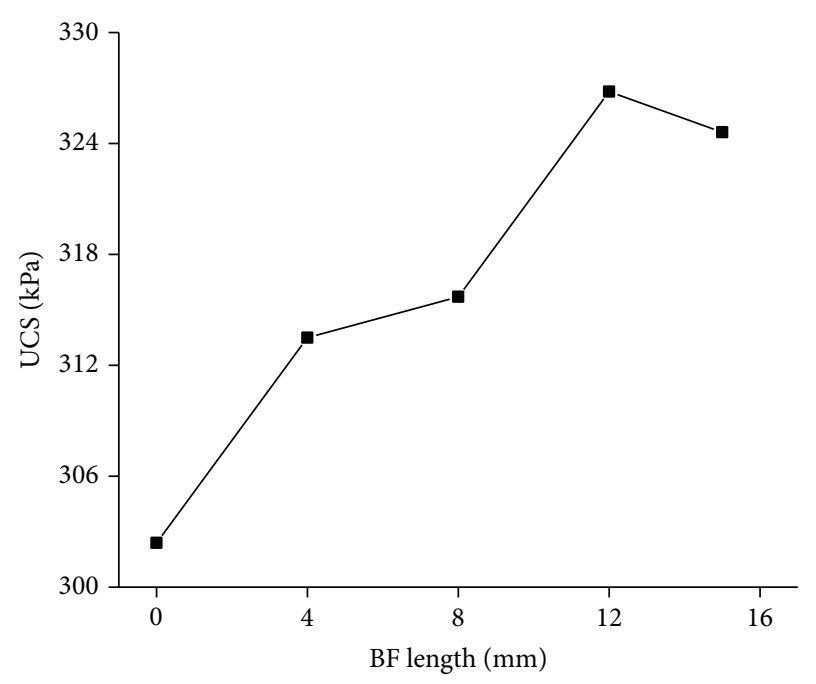

FIGURE 4: Effect of basalt fiber (BF) length on unconfined compressive strength (UCS) of soil samples.

gentler than the soil without fiber, and the strength stabilizes after a slight decline. Even the latter deformation part of some fiber reinforced soil samples is strain hardening. For example, in S10, the strength increases and achieves the higher value later. From Figure 2, it can also be seen that the curves of fiber reinforced soil are all above that of soil without fiber (S1) and maintain a certain distance. All these indicate that, compared with the soil without fiber, the fiber reinforced soil not only has a higher breaking strength, but also has a higher residual strength and more stable performance in the latter part of deformation. It is defined as "poststrong" characteristic of fiber reinforced soil in this paper.

Regarding "poststrong" characteristic of fiber reinforced soil, it is caused by the following reasons: the soil particles around the fibers are compacted constantly with increasing of sample deformation, and the porosity of the sample reduces while the density increases which makes the contact area 


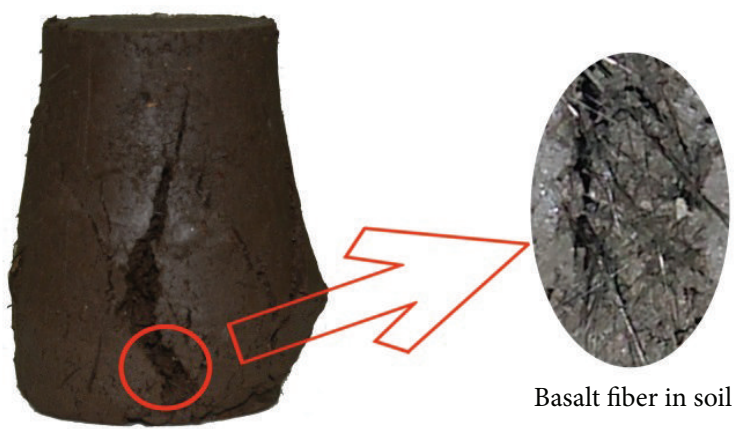

FIGURE 5: Failure form of basalt fiber reinforced soil sample.

between the fibers and surrounding soil particles increasing, as well as the normal force in the interface. This directly leads to the increasing of the friction between the fiber and soil. Thus, the fibers thereby prevent the soil particles under the external force from moving, which makes the strength of soil samples achieve a higher and relatively stable value later. It can also be drawn that the strength of fiber reinforced soil has an important relationship with its compactness and high density benefits to fiber reinforced soil for achieving a higher value later.

Because the fiber reinforced soil has "poststrong" characteristic, the soil sample still has a large residual strength just when the damage occurs. Even if there are a lot of cracks, due to the friction between the fibers and soil particles increasing, the development of cracks is slow and has certain predictability. The soil samples present a good plasticity in the course of destruction (Figure 5).

5.2. Mechanism of Fiber Reinforced Clay. The results show that a certain content and length of basalt fiber can significantly improve the UCS of clay soil. However, it is not a simple linear relationship between content and length of the fiber to enhance the effect of soil strength. It is different from soil without fiber and ordinary method of modified clay soil. The basalt fiber reinforced clay soil has the "poststrong" characteristic in the destruction process. These are all associated with the mechanism of basalt fiber reinforced soil. At present, there are a few studies about the mechanism of basalt fiber reinforced clay soil. The reinforcement mechanism is discussed in the following three aspects in this paper.

5.2.1. Interaction between Fiber and Soil. Inside the basalt fiber reinforced clay soil, the fibers and soil particles actually interact with and constrain each other. The mode of interaction can be discussed as follows.

The single tiny fiber in the soil is wrapped by the soil particles, the fiber and soil particles contact with each other and produce interface force [15], and the interface force can be divided into the normal force and tangential force. The form of normal force is mainly extrusion pressure and cohesion, and the squeeze pressure is related to external pressure suffered by the soil sample, whereas the adhesive force is related to self-contained clay soil and cohesion. The tangential force is mainly in the form of friction, which has direct relation with the normal force, the greater normal force, and the greater friction. Under the unstressed condition, it is reflected in the form of static friction. When the soil sample is stressed and the strain of soil sample is produced, the static friction force is gradually transformed into sliding friction. In the initial deformation, when the soil sample is stressed, the fiber has two states: one is in a relatively free state, the fiber and soil particles are freely accessible, and the interfacial force exists while the fiber has no internal force; and the other is in a stress state, in the process of soil preparation, due to the disturbance of the soil, the portions of the fibers are in the state of being bent and twisted and other forms, and the presence of certain internal forces in fibers themselves is produced. The samples with such fibers have a certain initial stress, so they have a tendency of mutual dislocation between the soil particles and themselves. Therefore, the fibers suffer not only the normal force but also the tangential force.

With the increase of the external force and pressing force, the individual fiber suffers increasing normal force. Since the modulus of basalt fiber is much higher than that of the soil, when at the same force and in the initial free state, the free fibers and the stress fibers are bound to generate mutual dislocation deformation trend and eventually slide because of the inconsistency of deformation. This also makes the friction suffered by fibers transform from static friction into sliding friction and increase rapidly, and then the displacement and deformation of soil particles are constrained. But each fiber only constrains soil particles within a certain radius around itself; over the radius, the soil particles will not be bound by the constraint of fiber. From the perspective of transference of the internal stress, at this time, the inside of soil forms the fiber-soil column in which fiber acts as a center line and the surrounding soil particles are closely around the fiber at a certain radius (Figure 6(a)). It can clearly be seen in SEM micrograph of a fiber-soil mixture (Figure 7(a)). The surface of fiber is surrounded by clay particles closely which forms a fiber-soil column nearly. There are obvious shearing traces on the fragmentized clay particles and the soil particles are still on the surface of fiber rather than slip away. So there is stress transferring in the fiber-soil column. Particularly, the stress is transferred and suffered by a single fiber-soil column that actually consists of two parts: one is suffered by the inherent strength of soil without incorporated fibers. It is the basic stress transferred and suffered by the fiber-soil column. While the other part is suffered by the internal forces caused by interfacial forces, this is subsidiary stress transferred and suffered by the fiber-soil column due to the presence of the fibers. Because the interfacial force is the strongest in the fiber surface, the subsidiary stress here is also the strongest. Then it decays along the radial direction, until 0 at the outer surface of the fiber-soil column.

The discrete distribution of fibers in the soil is equivalent to forming a three-dimensional fiber-soil net, in which the fiber-soil column acts as a skeleton (Figure 6(b)). There will be superposition and transmission of stress at the part when the different fiber-soil columns intersect with each other. It can clearly be seen in SEM micrograph of fiber-soil mixture (Figure 7(b)). The fibers have joints by clay particles from 


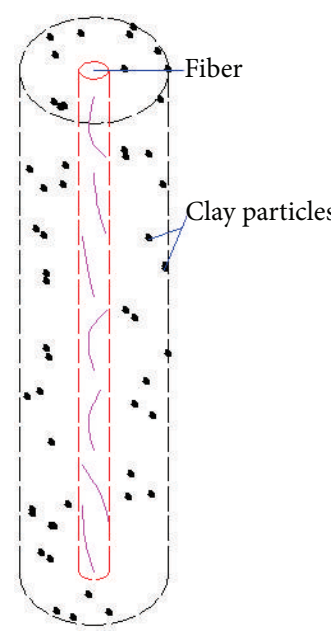

(a) Fiber-soil column

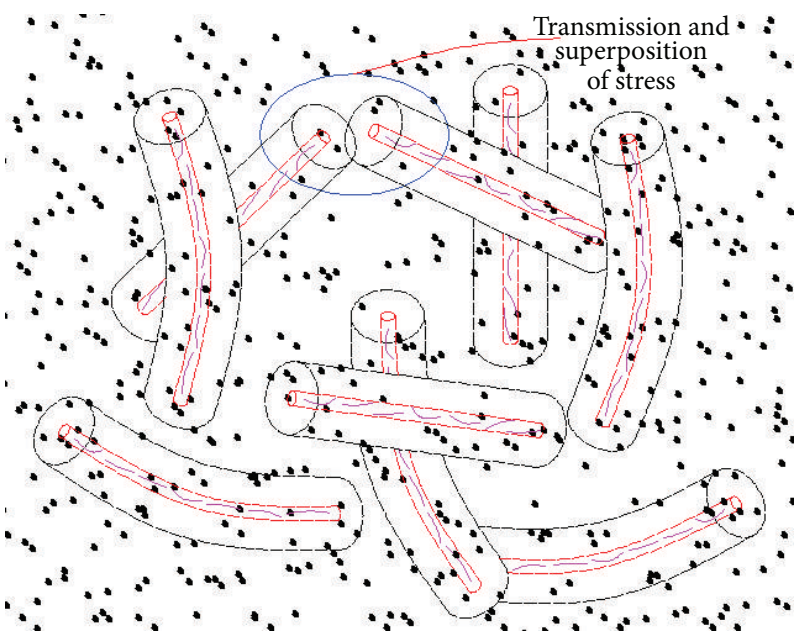

(b) Fiber-soil net

FIGURE 6: Model of fiber and soil column-net.

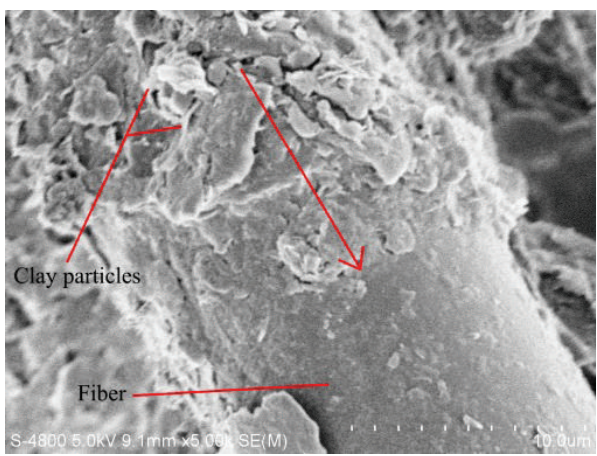

(a) Fiber-soil column

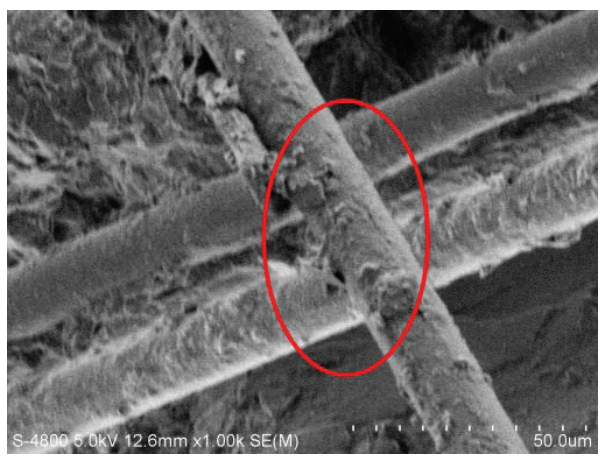

(b) Fiber-soil net

FIGURE 7: SEM micrograph of fiber-soil mixture.

each fiber-soil column. When the fiber reinforced soil is affected by external force and has deformation trend, the soil particles will transfer stress to the surrounding fibersoil column. Any parts of interwoven fiber-soil column will pass the stress and strain to link together with different directions of fiber-soil column. Therefore, the external force is transmitted to a larger space through three-dimensional distribution fiber-soil net. The part of the external stress converts to the internal force and thus prevents the increasing of the overall strain of soil sample. That is to say, compared with the soil without fiber, the improvement of strength for the fiber reinforced soil sample is born by the additional stress of fiber-soil net. Meanwhile the interwoven fiber-soil net also plays a role in binding the displacement and deformation of soil particles; it makes soil samples have higher strength and integrity.

5.2.2. Effect of Content. When the content of basalt fiber is rather little, the spacing of fiber is large, it is difficult for intersection between the fiber-soil columns, and thus the fiber and soil cannot form an effective fiber-soil net. When the soil suffers the external force, it is mainly transferred and carried by the scattered fiber-soil columns and forces between soil particles themselves. When the content of basalt fiber increases gradually, the spacing of fiber decreases which makes the adjacent fiber-soil columns intersect easily to form an effective fiber-soil net. So the soil suffers external force at this time, and it is mainly transferred and carried by the fiber-soil net and forces between soil particles. The soil is a whole unit which has a force skeleton structure. However, the test results show that the effect of reinforcement is not better when the basalt fiber content is higher. Because the interaction between fibers and soil is increasing when the content of basalt fiber content is increasing, while the frictional resistance between fibers is obviously lower than the interfacial force between the fiber and soil particles, it is difficult to prevent the overall deformation of soil from increasing by transforming the external force into the internal force of fibers in the form of the interfacial force. When the content of basalt fiber is rather more, a lot of fiber filaments would gather in clusters inside the soil sample due to the electrostatic interaction, which makes fibers difficult to be distributed uniformly. It is easy to form the weak area of stress, which is not conducive to the transference of 
stress. So the excess of fibers would reduce the effect of fiber reinforcement.

5.2.3. Effect of Length. When the length of basalt fiber is too short, the fiber-soil columns formed inside the soil are also too short. The subsidiary stress caused by surrounding soil particles is rather small, which is hard to constrain the whole fiber. It makes the fibers in soil slide easily. Therefore, it is difficult to effectively play the role in reinforcement. When the content of basalt fiber is low at this time, the contact between the fiber-soil columns is weaker and it makes the transmission and superposition of stress difficult. In this way, the fiber-soil net cannot be formed effectively. Compared with the soil without fiber, the strength of reinforced soil does not improve very much.

When the length of basalt fiber is too long, the strength of fiber is lower in tension, bending, torsion, and so on. In the process of the mixture of fibers and soil, they are in the stress state. Therefore, the strength of fiber-soil columns formed inside the soil is also lower in tension, bending, and torsion. And the initial stress exists in the fiber-soil columns at this time. The part of the initial stress like the tensile stress is beneficial for the soil strength, which improves the soil density, and the stress caused by bending and torsion is not beneficial for the soil strength, which makes the crack of soil and the sliding fissures inside soil form easily. The long fibers are mainly in the state of continuous bending when the soil is disturbed. For a single fiber, the initial stress caused by the continuous bending state can accelerate the attenuation of the subsidiary stress in the fiber-soil columns when transferring; it would result in the reduction of the fiber-soil column radius and strength.

However, when the content of basalt fiber is determined, the probability of contact between the fiber-soil columns is increased with the length of fiber, which makes the transmission and superposition of stress easier, and the fiber-soil net can be formed more effectively. It is beneficial to improve the overall strength of the soil. Through the analyses, the excessive length of fiber has both advantages and disadvantages for improving the strength of the soil when the content of basalt fiber is certain. Compared with the appropriately long fiber reinforced soil, it leads to the unobvious improvement of the strength for the overlong fiber reinforced soil, and even the strength would decline when the content of basalt fiber is too low.

\section{Conclusions}

(1) The UCS of clay soil can be effectively improved by the basalt fiber. When the length of fiber is a constant, the strength first increases and then has a downward trend with increasing the content of fiber, and the best content is $0.25 \%$. When the content of fiber is the same, the strength first increases and then decreases slightly with the fiber length increasing. The effect of reinforcement reaches the maximum with the length of $12 \mathrm{~mm}$.

(2) Different from the soil without fiber and ordinary way modified clay soil, the basalt fiber reinforced clay soil has the "poststrong" characteristic. Compared with the soil without fiber, it has the higher breaking strength and more stable performance. It is a plastic failure in the latter part of the deformation.

(3) About the mechanism of basalt fiber reinforced clay soil, the strength of clay soil is influenced through the interfacial force in the form of fiber-soil column and fiber-soil net based on the proposed fiber and soil column-net model and SEM images. The content of fiber will decide whether to form an effective fiber-soil net inside the soil. The electrostatic interaction between the fiber filaments cannot be ignored when the content of fiber is large. The length of fiber will affect the total stress and distribution pattern of fiber-soil net and thus affect the overall strength of soil samples.

\section{Conflict of Interests}

The authors declare that there is no conflict of interests regarding the publication of this paper.

\section{Acknowledgments}

Financial supports from the Fundamental Research Funds for the Central Universities of Hohai University (no. B15020060), China Postdoctoral Science Foundation (no. 2012M511193 and no. 2014T70468), Ph.D. Programs Foundation of Ministry of Education of China (no. 20120094120015), the Natural Science Foundation of Jiangsu Province (no. BK20130832), and the National Natural Science Foundation of China (Grant no. 51508159) are gratefully appreciated.

\section{References}

[1] M. Jamei, P. Villard, and H. Guiras, "Shear failure criterion based on experimental and modeling results for fiberReinforced clay," International Journal of Geomechanics, vol. 13, no. 6, pp. 882-893, 2013.

[2] S. S. Najjar, S. Sadek, and H. Taha, "Use of hemp fibers in sustainable compacted clay systems," in Geo-Congress 2014 Technical Papers@sGeo-characterization and Modeling for Sustainability, pp. 1415-1424, ASCE, 2014.

[3] A. Senol, S. B. Ikizler, E. Etminan, and G. Demir, "Improvement of low plasticity clayey soils using polypropylene fibers," in Proceedings of the Pavement Performance Monitoring, Modeling, and Management, pp. 1-8, Hubei, China, July 2014.

[4] J. Prabakar and R. S. Sridhar, "Effect of random inclusion of sisal fibre on strength behaviour of soil," Construction and Building Materials, vol. 16, no. 2, pp. 123-131, 2002.

[5] A. Mesbah, J. C. Morel, P. Walker, and K. Ghavami, "Development of a direct tensile test for compacted earth blocks reinforced with natural fibers," Journal of Materials in Civil Engineering, vol. 16, no. 1, pp. 95-98, 2004.

[6] R. Mattone, "Sisal fibre reinforced soil with cement or cactus pulp in bahareque technique," Cement and Concrete Composites, vol. 27, no. 5, pp. 611-616, 2005.

[7] M. J. Khattak and M. Alrashidi, "Durability and mechanistic characteristics of fiber reinforced soil-cement mixtures," The International Journal of Pavement Engineering, vol. 7, no. 1, pp. 53-62, 2006. 
[8] M. Di Ludovico, A. Prota, and G. Manfredi, "Structural upgrade using basalt fibers for concrete confinement," Journal of Composites for Construction, vol. 14, no. 5, pp. 541-552, 2010.

[9] J. Shi, H. Zhu, Z. Wu, R. Seracino, and G. Wu, "Bond behavior between basalt fiber-reinforced polymer sheet and concrete substrate under the coupled effects of freeze-thaw cycling and sustained load," Journal of Composites for Construction, vol. 17, no. 4, pp. 530-542, 2013.

[10] D. Wang, L. Wang, X. Gu, and G. Zhou, "Effect of basalt fiber on the asphalt binder and mastic at low temperature," Journal of Materials in Civil Engineering, vol. 25, no. 3, pp. 355-364, 2013.

[11] X. Gu, B. Peng, G. Chen, X. Li, and Y. Ouyang, "Rapid strengthening of masonry structures cracked in earthquakes using fiber composite materials," Journal of Composites for Construction, vol. 16, no. 5, pp. 590-603, 2012.

[12] Q. Wang, R. Tang, Q. Cheng, X. Wang, and F.-L. Liu, "Research on static triaxial mechanical properties of new cementsoil reinforced with polypropylene fiber," Advances in Materials Science and Engineering, vol. 2014, Article ID 532327, 10 pages, 2014.

[13] N. Cristelo, V. M. C. F. Cunha, M. Dias, A. T. Gomes, T. Miranda, and N. Araújo, "Influence of discrete fibre reinforcement on the uniaxial compression response and seismic wave velocity of a cement-stabilised sandy-clay," Geotextiles \& Geomembranes, vol. 43, no. 1, pp. 1-13, 2015.

[14] Ministry of Construction of the People's Republic of China, GB/T 50123-1999 Standard for Soil Test Method, China Planning Press, Beijing, China, 1999, (Chinese).

[15] C. Tang, B. Shi, W. Gao, F. Chen, and Y. Cai, "Strength and mechanical behavior of short polypropylene fiber reinforced and cement stabilized clayey soil," Geotextiles and Geomembranes, vol. 25, no. 3, pp. 194-202, 2007. 

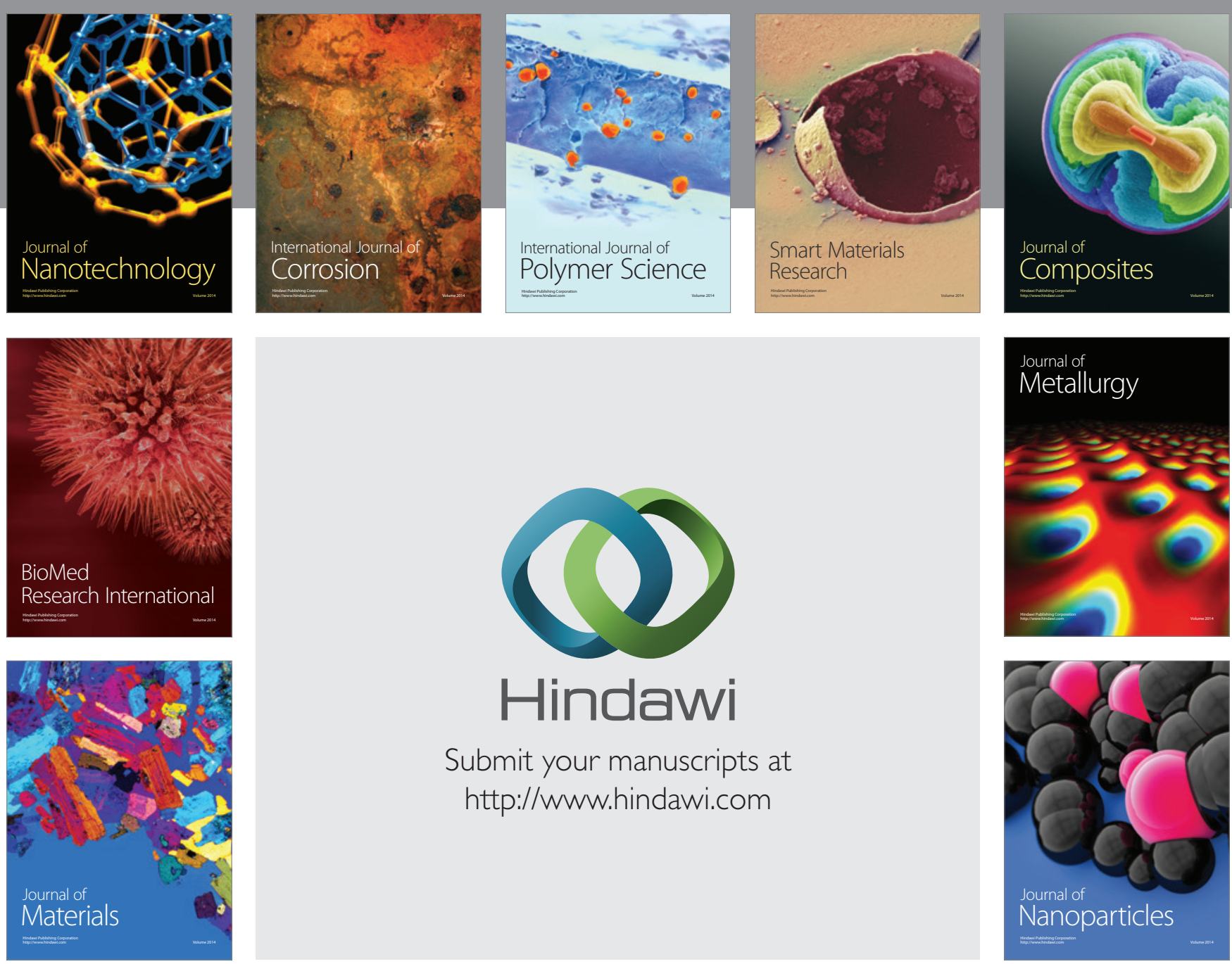

Submit your manuscripts at http://www.hindawi.com
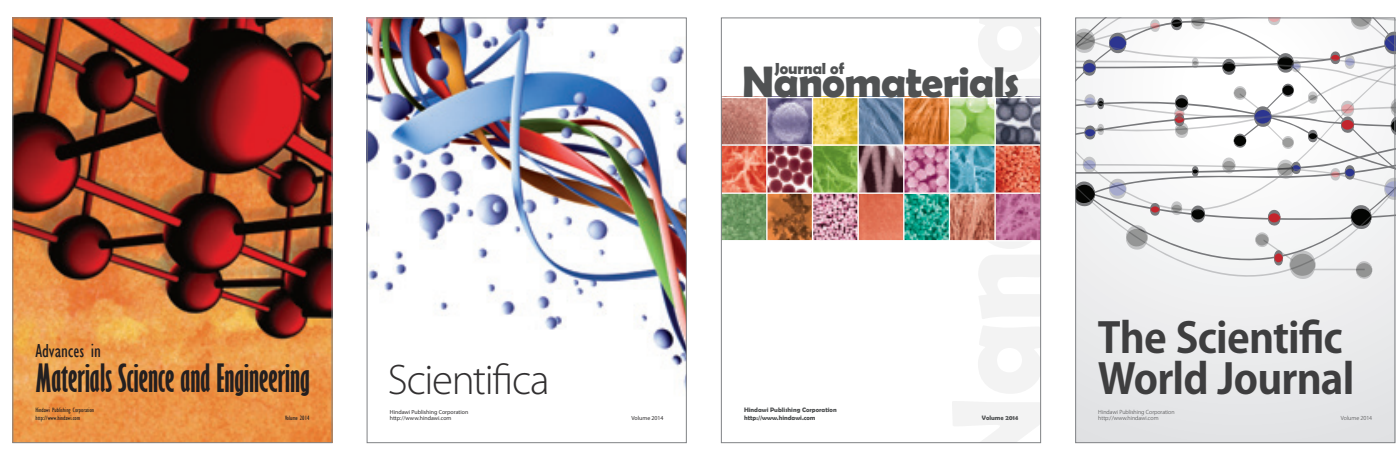

\section{The Scientific World Journal}
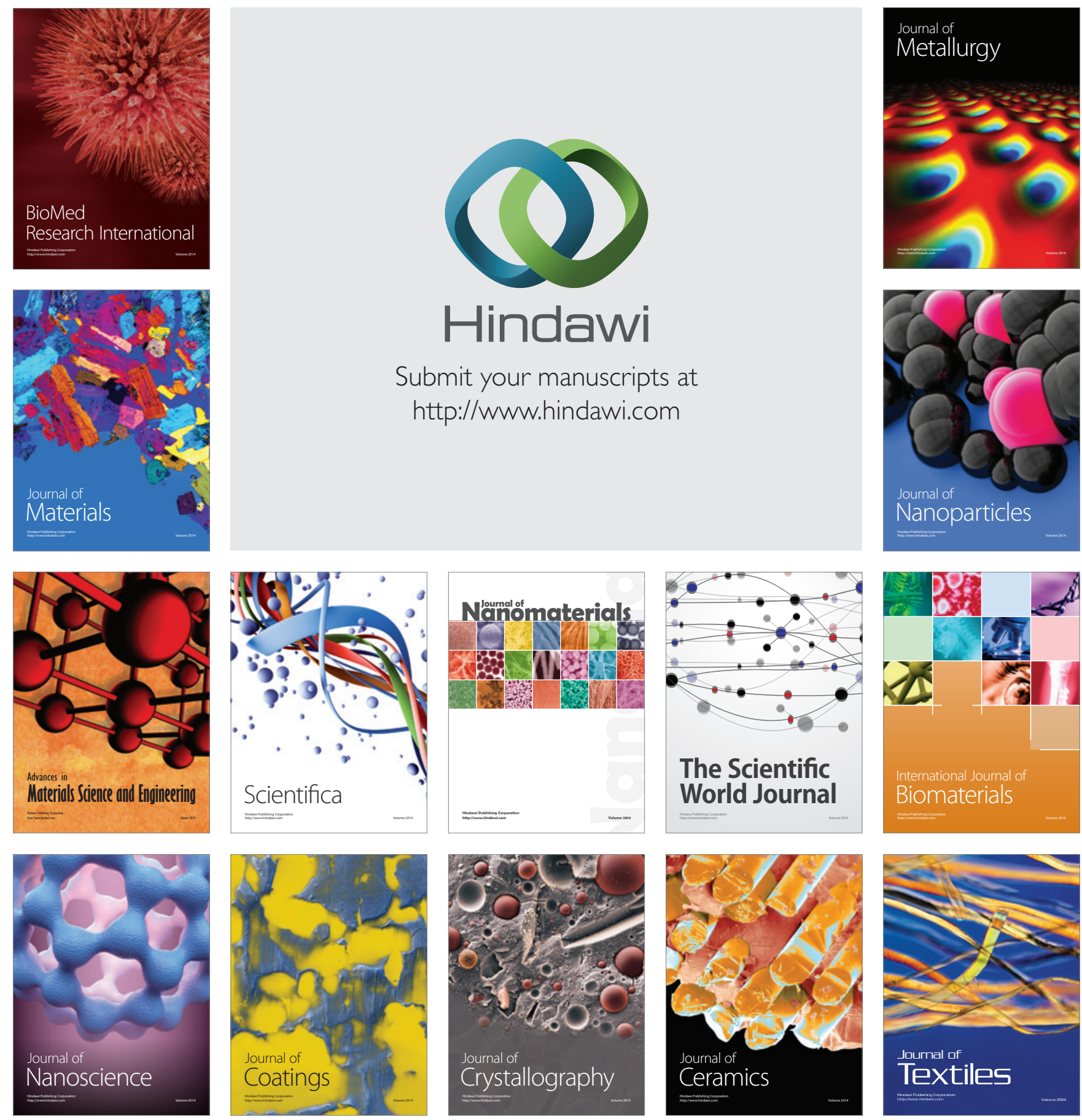